\title{
Kinetics and Mechanism of Pyridinolysis of Aryl Dithiocyclopentanecarboxylates in Acetonitrile
}

\author{
Hyuck Keun Oh \\ Department of Chemistry and Research Institute of Physics and Chemistry, Chonbuk National University, \\ Chonju 561-756, Korea.E-mail: ohkeun@chonbuk.ac.kr \\ Received May 12, 2010, Accepted June 10, 2010

\begin{abstract}
Kinetic studies on the pyridinolysis of aryl dithiocyclopentanecarboxyaltes 2 were carried out at $60.0{ }^{\circ} \mathrm{C}$ in acetonitrile. In the aminolysis of $\mathbf{2}$, the $\beta_{\mathrm{X}}$ values were $0.5-0.8$ with anilines, and there was no breakpoint. However, in the pyridinolysis of 2 , biphasic Brönsted plots were obtained, with a change in slope from a large value $\left(\beta_{\mathrm{X}} \cong 0.7\right)$ to a small value $\left(\beta_{\mathrm{X}} \cong 0.4\right)$ at $\mathrm{p} K_{\mathrm{a}}^{0}=5.2$. This was attributed to a change in the rate-limiting step from breakdown to the formation of a zwitterionic tetrahedral intermediate, $\mathrm{T}^{ \pm}$, in the reaction path, with an increase in the basicity of the pyridine nucleophile. An obvious change in the cross-interaction constant $\rho_{\mathrm{Xz}}$ from a large positive $\left(\rho_{\mathrm{XZ}}=+1.02\right)$ value to a small negative value $\left(\rho_{\mathrm{XZ}}=-0.17\right)$ supports the proposed mechanistic change.
\end{abstract}

Key Words: Nucleophilic substitution reaction, Pyridinolysis, Cross-interaction constant, Zwitterionic tetrahedral intermediate, Stepwise mechanism

\section{Introduction}

The transfer of a carbonyl (or thiocarbonyl) group among nucleophiles is one of the most extensively investigated subjects in mechanistic organic chemistry. ${ }^{1}$ The rate-determining step and transition state (TS) structure of acyl transfer reactions have been found to depend on the nucleophile, leaving and nonleaving groups, and solvent. ${ }^{1}$ In the aminolysis of aryl esters and carbonates, a biphasic dependence of the rate on amine basicity is often observed, with the slope changing from a large value $\left(\beta_{\text {nuc }} \geq 0.8\right)$ to a small value $\left(\beta_{\text {nuc }} \cong 0.1-0.3\right)$ at $\mathrm{p} K_{\mathrm{a}}^{0}$, where the amine and leaving group have the same expulsion rates from a zwitterionic tetrahedral intermediate, $\mathrm{T}^{ \pm}$. This has been attributed to a change in the rate-limiting step from the breakdown to the formation of $\mathrm{T}^{ \pm}$with an increase in the basicity of the amine.

The aminolysis of dithio esters 1 has been reported in water ${ }^{1 c, 2}$ and in acetonitrile ${ }^{3}$ with various amines, e.g., benzylamines, anilines, alicyclic secondary amines, pyridines, etc. For example, the aminolysis of dithio esters with benzylamines ${ }^{3 \mathrm{c}-\mathrm{d}}$ in acetonitrile exhibited rather

$$
\begin{gathered}
\| \\
\mathbb{R}-\mathrm{C} \\
1
\end{gathered}
$$

high $\mathrm{p}_{\mathrm{a}}{ }^{0}$ values $(>9.0)$, whereas that with pyridines ${ }^{3 \mathrm{f}-\mathrm{g}}$ gave low $\mathrm{p} K_{\mathrm{a}}{ }^{0}$ values $(\leq 5.0)$. On the other hand, our recent results on the pyridinolysis of aryl dithioacetates ${ }^{3 \mathrm{~g}}(\mathrm{R}=\mathrm{Me}$ in $\mathbf{1})$ and aryl furan-2-carbodithioates ${ }^{3 \mathrm{e}}\left(\mathrm{R}=\mathrm{C}_{4} \mathrm{H}_{4} \mathrm{O}\right.$ in 1$)$ in acetonitrile at $60.0{ }^{\circ} \mathrm{C}$ indicated that the effect of the acyl group (R) on the $\mathrm{p} K_{\mathrm{a}}^{0}$ value is insignificant with a similar $\mathrm{p} K_{\mathrm{a}}^{0}$ value of 5.2. This means that in acyl group transfer reactions, the breakpoint $\mathrm{p} K_{\mathrm{a}}{ }^{0}$ in a biphasic plot of rate $v s$. basicity of amine depends on the nucleophile and leaving group, but seems practically independent of the acyl group. This is quite plausible because $\mathrm{p} K_{\mathrm{a}}^{0}$ depends on the $\mathrm{p} K_{\mathrm{a}}$ values of the nucleophile (amine) and leaving group, but should be independent of the acyl group.

In this work, we report the results of kinetic studies on the pyridinolysis of aryl dithiocyclopentanecarboxylates $\mathbf{2}$ in acetonitrile at $60.0{ }^{\circ} \mathrm{C}$ (eq. 1). The aim was to complete the

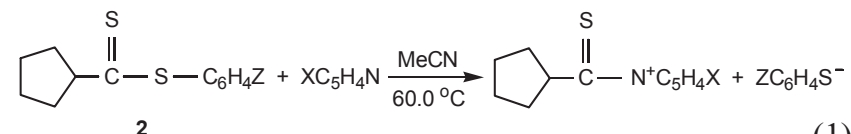

$\mathrm{X}=4-\mathrm{MeO}$, 4-Me, 3-Me, 4- $\mathrm{C}_{6} \mathrm{H}_{4} \mathrm{CH}_{2}, \mathrm{H}, 3-\mathrm{Ph}, 3-\mathrm{MeCO}$, 3-Cl, and 4-MeCO $\mathrm{Z}=4-\mathrm{Me}, \mathrm{H}, 4-\mathrm{Cl}$, and $4-\mathrm{Br}$

previous studies ${ }^{4}$ on the aminolysis of $\mathbf{2}$ and to further clarify the influence of the amine nature on the $\mathrm{p} K_{\mathrm{a}}^{0}$ value. We especially wanted to demonstrate that the breakpoint $\mathrm{p} K_{\mathrm{a}}^{0}$ in biphasic Brönsted plots has a much lower $\mathrm{p} K_{\mathrm{a}}$ value than the corresponding point for carbonyl esters. As an additional investigation to elucidate the mechanism, we determined the cross-interaction constant ${ }^{5} \rho_{\text {XZ }}$ in eqs. $2 \mathrm{a}$ and $2 \mathrm{~b}$, where $\mathrm{X}$ and $\mathrm{Z}$ represent the substituents in the nucleophile and leaving group, respectively.

$$
\begin{aligned}
& \log \left(k_{\mathrm{XZ}} / k_{\mathrm{HH}}\right)=\rho_{\mathrm{X}} \sigma_{\mathrm{X}}+\rho_{\mathrm{Z}} \sigma_{\mathrm{Z}}+\rho_{\mathrm{XZ}} \sigma_{\mathrm{X}} \sigma_{\mathrm{Z}} \\
& \rho_{\mathrm{XZ}}=\partial \rho_{\mathrm{X}} / \partial \sigma_{\mathrm{Z}}=\partial \rho_{\mathrm{Z}} / \partial \sigma_{\mathrm{X}}
\end{aligned}
$$

\section{Results and Discussion}

The reactions obeyed the simple kinetic law given by eqs. 3 and 4, where $\mathrm{ArS}^{-}$is a thiophenoxide ion and Py is pyridine. The plots of $k_{\mathrm{obs}} v s$. [Py] were linear, and the second-order rate constants $\left(k_{\mathrm{N}}\right)$ were obtained from the slopes of these plots. The $k_{\mathrm{N}}$ values are summarized in Table 1.

$$
\mathrm{d}\left[\mathrm{ArS}^{-}\right] / \mathrm{d} t=k_{\text {obs }}[\text { Substrate }]
$$


Table 1. Second-order rate constants $k_{\mathrm{N}}\left(\times 10^{3} \mathrm{M}^{-1} \mathrm{~s}^{-1}\right)$ and selectivity parameters ${ }^{a} \rho_{\mathrm{X}}, \rho_{\mathrm{Z}}, \rho_{\mathrm{XZ}}$, and $\beta_{\mathrm{X}}$, for reaction of Z-phenyl dithiocyclopentanecarboxylates with $\mathrm{X}$-pyridines in acetonitrile at $60.0{ }^{\circ} \mathrm{C}$

\begin{tabular}{|c|c|c|c|c|c|c|}
\hline \multirow{2}{*}{$\mathrm{X}$} & \multirow{2}{*}{$\mathrm{p} K_{\mathrm{a}}^{f}$} & \multicolumn{4}{|c|}{$\mathrm{Z}$} & \multirow{2}{*}{$\rho_{\mathrm{Z}}^{h}$} \\
\hline & & $4-\mathrm{CH}_{3}$ & $\mathrm{H}$ & $4-\mathrm{Cl}$ & $4-\mathrm{Br}$ & \\
\hline $4-\mathrm{CH}_{3} \mathrm{O}$ & 6.47 & 9.49 & 13.7 & 22.9 & 25.5 & $1.03 \pm 0.02$ \\
\hline $4-\mathrm{CH}_{3}$ & 6.00 & 6.56 & 9.59 & 15.9 & 17.8 & $1.02 \pm 0.02$ \\
\hline $3-\mathrm{CH}_{3}$ & 5.68 & 4.79 & 6.92 & 11.4 & 12.8 & $1.01 \pm 0.02$ \\
\hline 4- $\mathrm{C}_{6} \mathrm{H}_{5} \mathrm{CH}_{2}$ & 5.59 & 4.46 & 6.31 & 10.5 & 11.5 & $0.99 \pm 0.02$ \\
\hline $\mathrm{H}$ & 5.17 & 3.47 & 4.89 & 8.13 & 8.89 & $0.98 \pm 0.02$ \\
\hline $3-\mathrm{C}_{6} \mathrm{H}_{5}$ & 4.87 & 2.32 & 3.37 & 5.49 & 6.02 & $0.99 \pm 0.02$ \\
\hline $3-\mathrm{CH}_{3} \mathrm{CO}$ & 3.26 & 0.118 & 0.192 & 0.358 & 0.407 & $1.27 \pm 0.03$ \\
\hline $3-\mathrm{Cl}$ & 2.84 & 0.102 & 0.164 & 0.330 & 0.373 & $1.35 \pm 0.03$ \\
\hline $4-\mathrm{CH}_{3} \mathrm{CO}$ & 2.38 & 0.0338 & 0.0552 & 0.122 & 0.141 & $1.49 \pm 0.03$ \\
\hline$\rho_{\mathrm{X}}^{b, c}$ & & $-1.58 \pm 0.01$ & $-1.61 \pm 0.02$ & $-1.63 \pm 0.02$ & $-1.66 \pm 0.02$ & $\rho_{\mathrm{XZ}}^{b, i}=-0.17$ \\
\hline$\beta_{\mathrm{X}}^{b, d}$ & & $0.34 \pm 0.02$ & $0.35 \pm 0.02$ & $0.36 \pm 0.02$ & $0.36 \pm 0.02$ & \\
\hline$\rho_{\mathrm{X}}^{e, f}$ & & $-4.39 \pm 0.07$ & $-4.15 \pm 0.06$ & $-3.94 \pm 0.06$ & $-3.92 \pm 0.06$ & $\rho_{\mathrm{XZ}}{ }^{e, j}=+1.02$ \\
\hline$\beta_{\mathrm{X}}^{e, g}$ & & $0.71 \pm 0.10$ & $0.69 \pm 0.10$ & $0.65 \pm 0.10$ & $0.64 \pm 0.10$ & \\
\hline
\end{tabular}

${ }^{a}$ The values were taken from Hansch, C.; Leo, A.; Taft, R. W. Chem. Rev. 1991, 91, 165. The $\beta_{\mathrm{X}}$ values were determined using $\mathrm{p} K_{\mathrm{a}}$ values in $\mathrm{H}_{2} \mathrm{O}$. Justification for this procedure is provided in ref. 6 . The $\mathrm{p} K_{\mathrm{a}}$ values of pyridine in water at $25^{\circ} \mathrm{C}$ were taken from ref. 15 . The $\mathrm{p} K_{\mathrm{a}}$ values of $\mathrm{X}=3-\mathrm{C}_{6} \mathrm{H}_{5}$ and $\mathrm{X}=4-\mathrm{CH}_{3} \mathrm{CO}$ were taken from ref. $16 .{ }^{b} \mathrm{~F}$ or $\mathrm{X}=4-\mathrm{CH}_{3} \mathrm{O}, 4-\mathrm{CH}_{3}, 3-\mathrm{CH}_{3}, 4-\mathrm{C}_{6} \mathrm{H}_{5} \mathrm{CH}_{2}, \mathrm{H} .{ }^{c}$ Correlation coefficients are better than 0.998 in all cases. ${ }^{d}$ Correlation coefficients are better than 0.995 in all cases. ${ }^{e}$ For $\mathrm{X}=\mathrm{H}, 3-\mathrm{C}_{6} \mathrm{H}_{5}, 3-\mathrm{CH}_{3} \mathrm{CO}, 3-\mathrm{Cl}, 4-\mathrm{CH}_{3} \mathrm{CO} .{ }^{f}$ Correlation coefficients are better than 0.995 in all cases. ${ }^{g}$ Correlation coefficients are better than 0.995 in all cases. ${ }^{h}$ Correlation coefficients are better than 0.996 in all cases. ${ }^{i}$ Correlation coefficient is $0.997 .{ }^{j}$ Correlation coefficient is 0.993 .

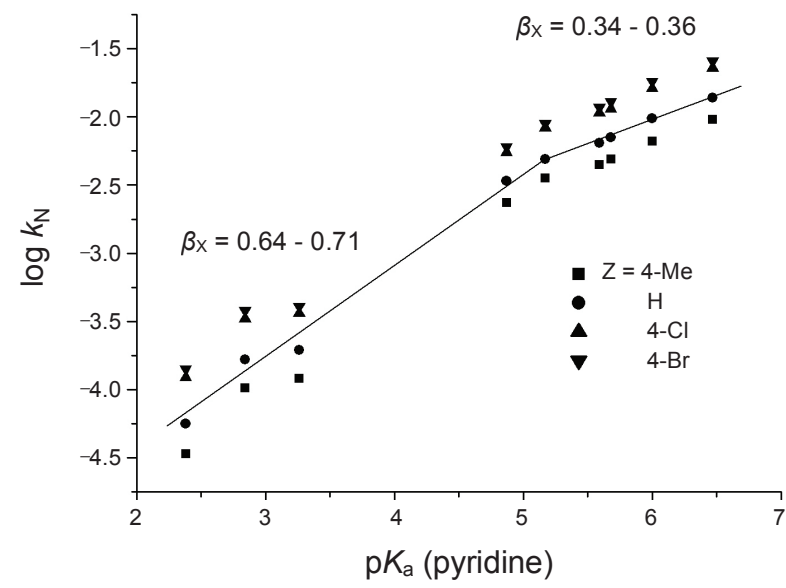

Figure 1. Brönsted plots for reactions of Z-aryl dithiocyclopentanecarboxylates with X-pyridines in acetonitrile at $60.0^{\circ} \mathrm{C}$.

$$
k_{\mathrm{obs}}=k_{\mathrm{N}}[\mathrm{Py}]
$$

The rates of pyridine nucleophiles $\left(k_{\mathrm{N}}=4.89 \times 10^{-3} \mathrm{M}^{-1} \mathrm{~s}^{-1}\right.$ at $60.0^{\circ} \mathrm{C}$ with $\left.\mathrm{Z}=\mathrm{H}\right)$ are slower than those of aniline $\left(k_{\mathrm{N}}=4.35 \times\right.$ $10^{-3} \mathrm{M}^{-1} \mathrm{~s}^{-1}$ at $10.0{ }^{\circ} \mathrm{C}$ with $\left.\mathrm{Z}=\mathrm{H}\right){ }^{4}$ The Brönsted plots that use the $k_{\mathrm{N}}$ and $\mathrm{p} K_{\mathrm{a}}$ values given in Table 1 are presented in Figure 1. The slopes are listed in Table 1, which also contains Hammett coefficients $\rho_{\mathrm{X}}\left(=\rho_{\text {nuc }}\right)$ and $\rho_{\mathrm{Z}}\left(=\rho_{\mathrm{lg}}\right)$ and cross-interaction constant $\rho_{\mathrm{XZ}}$. Although the $\beta_{\mathrm{X}}$ values are based on the plots of $\log$ $k_{\mathrm{N}}(\mathrm{MeCN}) v s . \mathrm{p} K_{\mathrm{a}}\left(\mathrm{H}_{2} \mathrm{O}\right)$, they can provide reasonable insights because a near constant $\Delta \mathrm{p} K_{\mathrm{a}}\left(=\mathrm{p} K_{\mathrm{a}}(\mathrm{MeCN})-\mathrm{p} K_{\mathrm{a}}\left(\mathrm{H}_{2} \mathrm{O}\right) \cong\right.$ 7.5) was found experimentally, ${ }^{6}$ as well as theoretically, ${ }^{7}$ and the slopes remain practically the same irrespective of whether $\mathrm{p} K_{\mathrm{a}}\left(\mathrm{H}_{2} \mathrm{O}\right)$ or $\mathrm{p} K_{\mathrm{a}}(\mathrm{MeCN})$ is used in the Brönsted correlation. It should be noted that the Brönsted plots in Figure 1 are biphasic, with a change in the slope. For $\mathrm{Z}=\mathrm{H}$, the slope changes from $\beta_{\mathrm{X}}=0.69$ to $\beta_{\mathrm{X}}=0.35$ at breakpoint $\left(\mathrm{p} K_{\mathrm{a}}^{0}=5.2\right)$ with an increase in the basicity of pyridine. The magnitude of $\beta_{\mathrm{X}}$ is somewhat smaller than those normally obtained $\left(\beta_{\mathrm{X}} \geq 0.8\right),{ }^{8}$ but it is well within the range $\left(\beta_{\mathrm{X}} \geq 0.7-0.8\right.$ in water ${ }^{9}$ and $\beta_{\mathrm{X}} \geq 0.6$ 0.7 in acetonitrile ${ }^{10}$ ) of the corresponding values for stepwise reactions with rate-limiting expulsions of the leaving group. For example, in the aminolysis of ethyl $S$-aryl thiolcarbonates with secondary alicyclic amines in water, the slopes were $\beta \mathrm{x}=0.7$ $0.8,{ }^{9}$ whereas in the pyridinolysis of $S$-phenyl 4-nitrobenzoates in acetonitrile, the slopes were $\beta \mathrm{x}=0.6-0.7,{ }^{10}$ both of which were consistent with those stepwise mechanisms where the breakdown of a zwitterionic tetrahedral intermediate $\mathrm{T}^{ \pm}$determines the rate. The value of 0.35 obtained for the more basic pyridines, as listed in Table 1, is also consistent with those obtained for stepwise mechanisms in which the formation of $\mathrm{T}^{ \pm}$limits the rate. ${ }^{11}$ In the pyridinolysis of aryl dithioacetates $\mathrm{CH}_{3} \mathrm{C}(=\mathrm{S}) \mathrm{SC}_{6} \mathrm{H}_{4} \mathrm{Z}$, a biphasic plot with a slope change from $\beta \mathrm{x} \cong 0.9$ to a small value of $\beta \mathrm{x} \cong 0.4$ was observed with a breakpoint at $\mathrm{p} K_{\mathrm{a}}^{0}=5.2$. $^{3 \mathrm{~g}}$

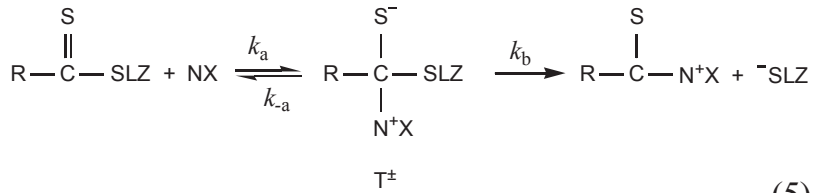

In this mechanism for pyridines with a high $\mathrm{p} K_{\mathrm{a}}$ value, $k_{-\mathrm{a}}$ 《 $k_{\mathrm{b}}$; therefore, the $k_{\mathrm{a}}$ step is the rate-determining step, i.e., $k_{\mathrm{N}}=$ $k_{\mathrm{a}}$, with a smaller Brönsted slope $\beta_{\mathrm{X}}(=0.34 \sim 0.36)$. On the other hand, at low $\mathrm{p} K_{\mathrm{a}}$ values, where $k_{-\mathrm{a}} \gg k_{\mathrm{b}}$ and $k_{\mathrm{N}}=\left(k_{\mathrm{a}} / k_{-\mathrm{a}}\right)$ $k_{\mathrm{b}}=K k_{\mathrm{b}}$, the $k_{\mathrm{b}}$ step should be rate-limiting, with a steeper Brönsted slope, $\beta_{\mathrm{X}}(=0.64 \sim 0.71)$. At the center of the Brön- 
Table 2. Second-order rate constants $k_{\mathrm{N}}$ Based on various temperatures and activation parameters ${ }^{a}$ for reactions of Z-phenyl dithiocyclopentanecarboxylates with $\mathrm{X}$-pyridines in acetonitrile.

\begin{tabular}{cccccc}
\hline $\mathrm{X}$ & $\mathrm{Z}$ & $\mathrm{t}\left({ }^{\circ} \mathrm{C}\right)$ & $\begin{array}{c}k_{\mathrm{N}} \\
\left(\times 10^{3} \mathrm{M}^{-1} \mathrm{~s}^{-1}\right)\end{array}$ & $\begin{array}{c}\Delta H^{\ddagger} \\
\left(\mathrm{kcal} \mathrm{mol}^{-1}\right)\end{array}$ & $\begin{array}{c}-\Delta S^{\ddagger} \\
\left(\mathrm{cal} \mathrm{mol}^{-1} \mathrm{~K}^{-1}\right)\end{array}$ \\
\hline & & 60.0 & 9.49 & & \\
$4-\mathrm{CH}_{3} \mathrm{O}$ & $4-\mathrm{CH}_{3}$ & 50.0 & 7.11 & 5.5 & 51 \\
& & 40.0 & 5.26 & & \\
4 & & 60.0 & 25.5 & & \\
$4-\mathrm{CH}_{3} \mathrm{O}$ & $4-\mathrm{Br}$ & 50.0 & 18.8 & 5.5 & 49 \\
& & 40.0 & 14.1 & & \\
& & 60.0 & 0.102 & & \\
$3-\mathrm{Cl}$ & $4-\mathrm{CH}_{3}$ & 50.0 & 0.0734 & 5.7 & 59 \\
& & 40.0 & 0.0535 & & \\
3 & & 60.0 & 0.373 & & \\
$3-\mathrm{Cl}$ & $4-\mathrm{Br}$ & 50.0 & 0.272 & 5.7 & 56 \\
& & 40.0 & 0.195 & & \\
\hline
\end{tabular}

${ }^{a}$ Calculated using the Eyring equation. The maximum errors calculated (by the method of K. B. Wiberg ${ }^{17}$ ) are $\pm 0.6 \mathrm{kcal} \mathrm{mol}^{-1}$ and \pm 2 e.u. for $\Delta H^{\star}$ and $\Delta S^{\ddagger}$, respectively.

sted curvature, $k_{-\mathrm{a}}=k_{\mathrm{b}}$, a pyridine with $\mathrm{p} K_{\mathrm{a}}=\mathrm{p} K_{\mathrm{a}}^{0}(=5.2)$ has the same leaving ability from tetrahedral intermediate $\mathrm{T}^{ \pm}$as the leaving group $\mathrm{ArS}^{-}$.

In the reactions of 2 , the $\beta_{\mathrm{X}}$ values were $0.5-0.8$ with anilines (at $10.0{ }^{\circ} \mathrm{C}$ ) and no breakpoints were observed. This means that $\mathrm{p} K_{\mathrm{a}}^{0} \geq 5.4$ (the highest $\mathrm{p} K_{\mathrm{a}}$ used; 4-methoxyaniline) for the reactions with anilines. The decreasing $\mathrm{p} K_{\mathrm{a}}{ }^{0}$ value is related to a decrease in the $k_{-\mathrm{a}} / k_{\mathrm{b}}$ ratio, with the value for aniline $(\geq 5.4)$ greater than that for pyridine $(=5.2)$. This decreasing value is also consistent with the general sequence for the amine expulsion $\left(k_{-a}\right)$ rates from the tetrahedral intermediate: primary amines $>$ secondary alicyclic amines $>$ anilines $>$ pyridines. ${ }^{12}$ In the aminolysis of 2 , the breakpoint $\mathrm{p} K_{\mathrm{a}}^{0}(=5.2)$, can be experimentally observed only in the reactions with pyridines because the $\mathrm{p} K_{\mathrm{a}}{ }^{0}$ value is higher than the basicities of the amines used in the reactions with anilines. This is why biphasic plots with a clear-cut breakpoint $\mathrm{p} K_{\mathrm{a}}^{0}$ are often observed in the aminolysis with pyridine nucleophiles, as in the pyridinolysis of aryl dithioacetates ${ }^{13}$ and aryl dithiocyclopentanecarboxylates in this work, both of which had $\mathrm{p} K_{\mathrm{a}}^{0}$ values of 5.2. The other reasons for the relatively low $\mathrm{p} K_{\mathrm{a}}^{0}$ value $(=5.2)$ for the pyridinolysis of two compounds of the dithio series: (i) Using the thiono $\left(\mathrm{S}^{-}\right)$series rather than the carbonyl $\left(\mathrm{O}^{-}\right)$series leads to a lower $\mathrm{p} K_{\mathrm{a}}^{0}$ caused by a decrease in the $k_{-\mathrm{a}} / k_{\mathrm{b}}$ ratio. This is because, in $\mathrm{T}^{ \pm}$, the lower proclivity of $\mathrm{S}^{-}$to form a double bond and expel a leaving group, compared to $\mathrm{O}^{-}$, leads to an amine expulsion from $\mathrm{T}^{ \pm}$that is slower ( $\operatorname{smaller} k_{-\mathrm{a}}$ ) than $\operatorname{ArS}^{-}$leaving $\left(k_{\mathrm{b}}\right){ }^{1}{ }^{1}$ (ii) The thiophenoxide leaving groups $\left(\mathrm{ZC}_{6} \mathrm{H}_{4} \mathrm{~S}^{-}\right)$that are used have lower basicities than the phenoxide leaving groups $\left(\mathrm{ZC}_{6} \mathrm{H}_{4} \mathrm{O}^{-}\right)$for the same $\mathrm{Z}$. Hence, $k_{\mathrm{b}}$ should be greater (with a decrease in $k_{-\mathrm{a}} / k_{\mathrm{b}}$ ), leading to a lower $\mathrm{p} K_{\mathrm{a}}{ }^{0}$ than the corresponding esters with a phenoxide leaving group.

The size of $\rho_{Z}$ in Table 1 also reflects the mechanistic change. The magnitudes of $\rho_{Z}$ change from large values $\left(\rho_{Z}=1.5\right)$ for the less basic pyridines to smaller values $\left(\rho_{Z} \cong 1.0\right)$ for the more basic pyridines; this is in agreement with the decrease in bond cleavage because the rate-determining step switches from the breakdown to the formation of the intermediate. Such a decrease in the magnitude of the $\rho_{Z}$ values from large $\left(\rho_{Z}=2.4\right.$ $3.2)$ to small values ( $\rho_{Z} \cong 2.3$ ) with the mechanistic change has also been reported in the pyridinolysis of aryl dithioacetates. ${ }^{13}$ Rough estimates of the $\beta_{Z}\left(=\beta_{\mathrm{lg}}\right)$ values indicate a decrease from $\beta_{\mathrm{Z}} \cong-0.5$ to $\beta_{\mathrm{Z}} \cong-0.3$ at the breakpoint, which agrees with the change in the rate-determining step.

A clear-cut change in the cross-interaction constant is another important result supporting the mechanistic change at $\mathrm{p} K_{\mathrm{a}}^{0}=$ 5.2 from the breakdown to the formation of $\mathrm{T}^{ \pm}$as the basicity of pyridine is increased. The cross-interaction constant changes from a relatively large positive value $\left(\rho_{\mathrm{XZ}}=+1.02\right)$ to a small negative value $\left(\rho_{\mathrm{XZ}}=-0.17\right)$ at the breakpoint. Similar changes in $\rho_{\mathrm{XZ}}$ values have been reported for the pyridinolysis of $S$-phenyl 4-nitrobenzoates ${ }^{10}\left(4-\mathrm{NO}_{2} \mathrm{C}_{6} \mathrm{H}_{4} \mathrm{C}(=\mathrm{O}) \mathrm{SC}_{6} \mathrm{H}_{4} \mathrm{Z}\right)$ and aryl dithioacetates ${ }^{13}\left(\mathrm{CH}_{3} \mathrm{C}(=\mathrm{S}) \mathrm{SC}_{6} \mathrm{H}_{4} \mathrm{Z}\right)$. In the former, the $\rho_{\mathrm{Xz}}$ value changed from +1.41 to -0.32 at $\mathrm{p} K_{\mathrm{a}}{ }^{0} \cong 4.2$, and in the latter, it changed from +1.34 to -0.15 at $\mathrm{p} K_{\mathrm{a}}{ }^{0}=5.2$, as the basicity of pyridine was increased. These are interpreted to indicate mechanistic changes from the breakdown to the formation of $\mathrm{T}^{ \pm}$. These changes in the $\rho_{\mathrm{Xz}}$ values with changes in the reaction mechanism give further credence to the use of the cross-interaction constant as a useful mechanistic criterion.

Table 2 lists the activation parameters $\Delta H^{*}$ and $-\Delta S^{*}$ for the pyridinolysis of 2 . The values of $\Delta H^{\star}$ and $-\Delta S^{\star}$ are smaller for a more basic pyridine $\left(\mathrm{X}=4-\mathrm{OCH}_{3}\right)$ than for a less basic pyridine $(\mathrm{X}=3-\mathrm{Cl})$. Although the differences are small, they are significant enough to be over the error limits. These trends are in accordance with the breakdown step (for $\mathrm{X}=3-\mathrm{Cl}$ ) requiring higher energy and lower (more negative) entropy in the TS due to bond cleavage to two ionic products (eq. 2).

In summary, kinetic studies on the pyridinolysis of aryl dithiocyclopentanecarboxyaltes 2 were carried out at $60.0{ }^{\circ} \mathrm{C}$ in acetonitrile. In the aminolysis of $\mathbf{2}$, the $\beta_{\mathrm{X}}$ values were $0.5-0.8$ with anilines, and there was no breakpoint. However, in the pyridinolysis of $\mathbf{2}$, biphasic Brönsted plots were obtained, with a slope change from a large value $\left(\beta_{\mathrm{X}} \cong 0.7\right)$ to a small value $\left(\beta_{\mathrm{X}} \cong 0.4\right)$ at $\mathrm{p} K_{\mathrm{a}}^{0}=5.2$. This slope change was attributed to a change in the rate-limiting step from the breakdown to the formation of a zwitterionic tetrahedral intermediate $\mathrm{T}^{ \pm}$in the reaction path with an increase in the basicity of the pyridine nucleophile. A clear-cut change in the cross-interaction constant $\rho_{\mathrm{XZ}}$ from a large positive value $\left(\rho_{\mathrm{XZ}}=+1.02\right)$ to a small negative value $\left(\rho_{\mathrm{XZ}}=-0.17\right)$ supports the proposed mechanistic change. Other selectivity parameters $\left(\rho_{\mathrm{X}}\right.$ and $\left.\rho_{\mathrm{Z}}\right)$ and activation parameters $\left(\Delta H^{*}\right.$ and $\left.\Delta S^{*}\right)$ are also consistent with the proposed mechanism, as is the adherence to the reactivity selectivity principle (RSP).

\section{Experimental Section}

Materials. Acetonitrile (Merk, GR grade) was used after three distillations. The pyridine nucleophiles (Aldrich, GR grade) were used without further purification. The preparation and analytical data are reported elsewhere. ${ }^{12}$

Kinetic measurement. The rates were measured conductometrically in acetonitrile. The conductivity bridge used in this 
work was a homemade computer-automated A/D converter conductivity bridge. Pseudo first-order rate constants $k_{\text {obs }}$ were determined by the Guggenheim method ${ }^{14}$ with a large excess of pyridine (Py). Second-order rate constants $k_{2}$ were obtained from the slope of a plot of $k_{\mathrm{obs}} v s$. [Py] with more than five concentrations of pyridine. The $k_{2}$ values in Table 1 are the averages of more than three runs, and were reproducible to within $\pm 3 \%$.

Product analysis. The substrate, $p$-bromophenyl dithiocyclopentanecarboxylate ( 0.05 mole), was reacted with excess 4-picoline $(0.5$ mole $)$ with stirring for more than 15 half-lives at $60.0{ }^{\circ} \mathrm{C}$ in acetonitrile. The salt was filtered, and the solvent was removed from the precipitate. An analysis of the product gave the following results.

c- $\mathbf{C}_{5} \mathbf{H}_{9} \mathbf{C}(=\mathbf{S}) \mathbf{N}^{+} \mathbf{C}_{5} \mathbf{H}_{4}-p-\mathbf{C H}_{3}{ }^{-} \mathbf{S C}_{6} \mathbf{H}_{4}-\mathbf{4}-\mathrm{Br}: \mathrm{mp} 65-67{ }^{\circ} \mathrm{C}$, ${ }^{1} \mathrm{H}$ NMR (400 MHz, $\left.\mathrm{CDCl}_{3}\right), 1.38\left(8 \mathrm{H}, \mathrm{m}, \mathrm{CH}_{2}\right), 1.48(3 \mathrm{H}, \mathrm{s}$, $\left.\mathrm{CH}_{3}\right), 2.37$ (1H, m, CH), 7.26-7.30 (2H, dd, pyridine), 7.32-7.36 (9H, m, phenyl), 7.36-7.39 (2H, d, pyridine); ${ }^{13} \mathrm{C}$ NMR (100.4 $\left.\mathrm{MHz}, \mathrm{CDCl}_{3}\right), 230.1(\mathrm{C}=\mathrm{S}), 135.8,135.3,132.3,132.1,132.0$, 129.8, 129.5, 52.7, 30.5, 27.2, $25.1\left(\mathrm{CH}_{3}\right) ; v_{\max }(\mathrm{KBr}), 1567$, $1456(\mathrm{C}=\mathrm{C}$, phenyl), $1230(\mathrm{C}=\mathrm{S}), 857(\mathrm{C}-\mathrm{H}$, pyridine $), 802$ (C-H, phenyl); mass, $\mathrm{m} / z 394\left(\mathrm{M}^{+}\right)$. Anal. Calcd for $\mathrm{C}_{18} \mathrm{H}_{20} \mathrm{Br}-$ $\mathrm{NS}_{2} ; \mathrm{C}, 54.8 ; \mathrm{H}, 5.11$. Found C, 54.6; H. 5.13.

Acknowledgments. This paper was supported by research funds of Chonbuk National University in 2010.

\section{References}

1. (a) Page, M. I.; Williams, A. Organic and Bio-organic Mechanisms; Longman: Harlow, 1997; Ch. 7. (b) Williams, A. Concerted Organic and Bio-Organic Mechanisms; CRC Press: Boca Raton, 2000; Ch. 4. (c) Castro, E. A. Chem. Rev. 1999, 99, 3505.

2. (a) Castro, E. A.; Ibanez, F.; Santos, J. G.; Ureta, C. J. Chem. Soc., Perkin Trans. 2 1991, 1919. (b) Castro, E. A.; Ibanez, F.; Santos, J. G.; Ureta, C. J. Org. Chem. 1992, 57, 7024. (c) Cabrera, M.; Castro, E. A.; Salas, M.; Santos, J. G.; Sepulveda, P. J. Org. Chem. 1991, 56, 5324. (d) Castro, E. A.; Cubillos, M.; Ibanez, F.; Moraga, I.; Santos, J. G. J. Org. Chem. 1993, 58, 5400. (e) Castro, E. A.; Ibanez, F.; Salas, M.; Santos, J. G.; Sepulveda, P. J. Org. Chem. 1993, 58,459 .
3. (a) Oh, H. K.; Shin, C. H.; Lee, I. J. Chem. Soc., Perkin Trans. 2 1995, 1169. (b) Oh, H. K.; Woo, S. Y.; Shin, C. H.; Park, Y. S.; Lee, I. J. Org. Chem. 1997, 62, 5780. (c) Oh, H. K.; Kim, S. K.; Cho, I. H.; Lee, H. W.; Lee, I. J. Chem. Soc., Perkin Trans. 2 2000, 2306. (d) Oh, H. K.; Kim, S. K.; Lee, H. W.; Lee, I. New J. Chem. 2001, 25, 313. (e) Oh, H. K.; Kim, S. K.; Lee, H. W.; Lee, I. J. Chem. Soc., Perkin Trans. 2 2001, 1753. (f) Oh, H. K.; Ku, M. H.; Lee, H. W.; Lee, I. J. Org. Chem. 2002, 67, 8995. (g) Oh, H. K.; Ku, M. H.; Lee, H. W.; Lee, I. J. Org. Chem. 2002, 67, 3874. (h) Oh, H. K.; Shin, C. H.; Lee, I. Bull. Korean Chem. Soc. 1995, 16, 657.

4. Jeong, K. S.; Oh, H. K. Bull. Korean Chem. Soc. 2008, $29,675$.

5. (a) Lee, I. Chem. Soc. Rev. 1990, 19, 317. (b) Lee, I. Adv. Phys. Org. Chem. 1992, 27, 57. (c) Lee, I.; Lee, H. W. Collec. Czech. Chem. Commun. 1999, 64, 1529.

6. (a) Coetzee, J. F. Prog. Phys. Org. Chem. 1965, 4, 45. (b) Spillane, W. J.; Hogan, G.; McGrath, P.; King, J.; Brack. C. J. Chem. Soc., Perkin Trans. 2 1996, 2099. (c) Foroughifar, N.; Leffek. K. T.; Lee, Y. G. Can. J. Chem. 1992, 70, 2856.

7. Lee, I.; Kim. C. K.; Han. I. S.; Lee, H. W.; Kim, W. K.; Kim, Y. B. J. Phys. Chem. B 1999, 103, 7302.

8. (a) Gresser, M. J.; Jencks, W. P. J. Am. Chem. Soc. 1977, 99, 6963. (b) Castro, E. A.; Ureta, C. J. Org. Chem. 1990, 55, 1076. (c) Castro, E. A.; Araneda, C. A.; Santos, J. G. J. Org. Chem. 1997, 62, 126. (d) Castro, E. A. Chem. Rev. 1999, 99, 3505.

9. Castro, E. A.; Cubillos, M.; Santos, J. G. J. Org. Chem. 1999, 64, 6342 .

10. Koh, H. J.; Han, K. L.; Lee, I. J. Org. Chem. 1999, 64, 4783.

11. Gresser, M. J.; Jencks, W. P. J. Am. Chem. Soc. 1977, 99, 6963.

12. Oh, H. K.; Woo, S. Y.; Shin, C. H.; Lee, I. Int. J. Chem. Kinetic 1998, 30, 849.

13. Oh, H. K; Ku, M. H.; Lee, H. W.; Lee, I. J. Org. Chem. 2002, 67, 3874.

14. (a) Guggenheim, E. A. Philos, Mag. 1926, 2, 538. (b) Park, S. Y.; Oh, H. K. Bull. Korean Chem. Soc. 2009, 30, 749. (c) Oh, H. K.; Hong, S. K. Bull. Korean Chem. Soc. 2009, 30, 2453.

15. (a) Albert, A.; Serjeant, E. P. The Determination of Ionization Constants, 3rd ed.; Chapman and Hall: New York, 1984; pp 154-155. (b) Dean, J. A. Handbook of Organic Chemistry; McGraw-Hill: New York, 1987; Ch. 8. (c) Fischer, A.; Galloway, J. A.; Vaughan, J. J. Chem. Soc. 1964, 3591.

16. (a) Koh, H. J.; Han, K. L.; Lee, I. J. Org. Chem. 1999, 64, 4783. (b) Koh, H. J.; Han, K. L.; Lee, H. W.; Lee, I. J. Org. Chem. 1998, 63, 9834.

17. Wiberg, K. B. Physical Organic Chemistry; Wiley: New York, 1964; p 378. 